\title{
A Study of the Circulation Patterns Affecting Drought and Wet Years in Central Iran
}

\author{
Kamal Omidvar, ${ }^{1}$ Mehran Fatemi, ${ }^{1}$ \\ Mahdi Narangifard, ${ }^{1}$ and Khodakaram Hatami Bahman Beiglou ${ }^{2}$ \\ ${ }^{1}$ Yazd University, Yazd, Iran \\ ${ }^{2}$ Isfahan University, Isfahan, Iran \\ Correspondence should be addressed to Mehran Fatemi; yazdfatemi@yahoo.com
}

Received 5 November 2015; Revised 20 January 2016; Accepted 17 February 2016

Academic Editor: Fateh Chebana

Copyright (C) 2016 Kamal Omidvar et al. This is an open access article distributed under the Creative Commons Attribution License, which permits unrestricted use, distribution, and reproduction in any medium, provided the original work is properly cited.

The main objective of this research is to identify atmospheric circulation patterns involved in the occurrence of wet and dry periods using the PCA method. To this end, drought and wet periods (1982-2011) were calculated in central Iran. The results of PCA indicated that $42 \%$ of variance in geopotential height data at $500 \mathrm{HPa}$ level was associated with the extension of subpolar lows elevation towards lower latitudes, which transmitted high elevation areas like Siberian highs to the south and formed high atmospheric stability in the study area. Therefore, the dominance of high elevation cores on the area was characterized by cold air descent and cloudlessness, which led to low precipitation and drought events. Moreover, the eight components in wet periods could explain $94 \%$ of data variation in geopotential height data. The results of PCA in wet period suggested that the first component with the highest frequency played a key role among circulation patterns, determining the dominant pattern in cold period of the year. Further, its negative phase indicated polar and Siberian highs with the remaining components, given the negative and positive phases of the centers, revealing atmospheric instability that entered the region from Mediterranean, Black, and Red sea, thereby marking the transition of the area from drought to the wet period.

\section{Introduction}

Precipitation is one of the most apparent atmosphere phenomena with considerable spatial and temporal diversity in Iran. The permanent interactions of atmospheric circulation systems during the year give rise to such dominant and extensive diversity $[1,2]$.

A better understanding of the mechanism and performance atmospheric circulation patterns and the factors affecting partial precipitation events is of great importance, with this kind of precipitation being able to cause flood and catastrophic consequences. Thus, it is necessary to identify formation mechanism, strengthening, and regulation governing the movement and expansion of precipitation climatic systems to gain benefit from its positive effects and eliminate or at least minimize its detrimental results [3]. Probabilistic assessment and prediction of drought provides valuable information for water resources planners and policy makers for developing drought mitigation strategies [4]. Drought is a complex phenomenon whose severity is related to a specific climatic region and local energy and water balance status [5].

In this respect, besides investigating the drought periods, it is also necessary to investigate and analyze the wet periods. Wet and dry periods along with natural phenomena like drought shape the atmospheric circulation patterns in a region by changing the frequency and impact [6]. Given the close relationship between atmospheric circulation patterns and climatic elements, extreme weather phenomena like flood and drought and dry and wet periods can be attributed to variations of atmospheric circulation patterns [7]. Drought is one of the extreme weather and natural hazards with higher frequency in arid and semiarid regions. Drought, as an important natural disaster, can affect different aspects of human life. This disaster represents a catastrophic weather condition which affects societies directly by limiting the accessibility of water resources, with enormous economic, social, and environmental costs [8]. Drought is the most complicated but least known natural hazard with a wider 
range of impact compared to other hazards [9]. Galambosi et al. [10] used principal component methods and multiaverage cluster analysis to assess and analyze the atmospheric daily circulation patterns at level of $500 \mathrm{HPa}$ above the southwest of United States. Svensson [11] applied principal component analysis method to the data of 700 and $800 \mathrm{HPa}$ with perceptible water. In this synoptic-statistical analysis, principal component analysis method along with Varimax rotation was applied to the data, and during two seasons of December to February and June to September. Kassomenos [12] used different methods like principal component analysis, agent analysis, and cluster analysis for climate classification and identification of precipitation periods in a study on describing synoptic condition above the south of Greece in the second half of the 20th century. It was stated that the relationship between precipitation as the most variable atmosphere phenomenon and atmospheric circulation patterns was very strong. By identifying the atmospheric circulation patterns, variance, frequency, intensity, and spatial distribution of precipitation can be investigated and its underlying physical grounds can be expressed. Duckstein et al. [13] identified circular patterns causing flood in Arizona State. Corte-Real et al. [14] and Trigo and Dacamara [15] found that lower frequency of precipitation type of the weather and increased frequency of drought were the main reasons for reduced precipitation in Portugal in the second half of the 20th century.

Littman [16] classified the pressure and geopotential height of $500 \mathrm{HPa}$ using cluster analysis and investigated the link between weather types and precipitation in Mediterranean area. Studies showed that the negative phase pace of NAO (North Atlantic Oscillation) teleconnection pattern was associated with the increased winter precipitation and temperature decrease, while its positive phase pace was associated with reduced precipitation, temperature rise, and winter drought across Turkey. Girardin et al. [17] studied the variations of summer drought in Boreal, Canada, in terms of the synoptic circulation of the atmosphere scale. Results showed that eastern Boreal is under the influence of two huge components of zonal scale and atmospheric meridian.

Yetemen and Yalcin [18] investigated the relationship of monthly average temperature in Afyon, Turkey, with teleconnection pattern index around North Mazandaran Sea, showing that, in the positive phase of teleconnection pattern of the North Mazandaran Sea, the air temperature had increased in the Afyon mountainous area, providing a proper condition from the convenience of tourists in that area. Büntgen et al. [19] investigated summer drought in Germany finding that, from a synoptic view point, the high pressure in the middle level of atmosphere above North Sea and low pressure on Southeast of Europe had led to summer drought. Parry et al. [20] studied the spatial and temporal development and large scale properties of European drought using synoptic analysis finding that, in the first phase of standard precipitation index (SPI) method, the emergence of a high pressure system across North Atlantic and its blocking in the direction of western winds have pushed precipitation systems towards southern Mediterranean, leading to the occurrence of drought in Europe. Croitoru and Toma [21] investigated the drought events in the central plain of Romania, arguing that air blocking in the advection path of tropical humid air mass was the reason of this event. Kutiel [22] studied the North Sea-Caspian teleconnection pattern on Middle East precipitation and temperature regimes, concluding that Middle East temperature system was sensitive to different phases of North Sea-Caspian teleconnection pattern, with sensitivity being greater in the negative $\operatorname{NCP}(-)$ phase and thereby leading to the increase in temperature in the Middle East. Rimkus et al. [23] investigated the atmospheric patterns during drought periods in Lithuania finding that drought intensity in the Baltic area is associated with the atmospheric circulation patterns. The negative phases of NAO/AO have provoked severe drought in the region. Peng et al. [24] investigated the probability of seasonal precipitation in China using large scale monthly atmosphere-oceanic indices. The results showed that sea surface temperature index in Western Pacific Ocean and Indian Ocean offered more effective predictions than El-Niño-Southern oscillation index.

Many studies on drought and wet years in Iran [4, 5, 2527] have been undertaken using various indicators, but there is still a paucity of studies based on principal components analysis and a lack of understanding concerning the regional structure of the atmospheric circulation in the event of wet and dry periods in central areas of Iran; therefore, the need for a research that focuses on the occurrence mechanism of the dry and wet periods in Central Iran and examines the structure of the atmospheric circulation on the region under study is strongly felt.

Also, given the high environmental sensitivity of arid and semiarid areas and the significant effect of wet and dry periods on the environment and agricultural practices, it is especially crucial to identify synoptic patterns underlying these periods. Thus, given the importance of this issue, the main goal of this study is to develop and implement a synoptic model for defining groups and patterns of atmospheric circulation that cause drought and rainfall patterns in the region. Therefore, in the present study, atmospheric circulation pattern at $500 \mathrm{HPa}$ level over Isfahan, Yazd, and Kerman provinces using principal component analysis and cluster analysis on the basis of wet years and dry years derived from the standard precipitation index (SPI) is investigated.

\section{Data and Method}

The study area consists of six synoptic stations of Kashan, Isfahan, Eastern Isfahan, Yazd, Kerman, and Bam located in Isfahan, Yazd, and Kerman provinces of Iran. The geographic location of the study area is shown in Figure 1. Central Iran is a steppe-like plateau characterized by extremely wet climate in the Northern regions, arid and semiarid conditions surrounded by desert with no recorded rainfall for years, and mountains (Zagros on the west and Alborz on the north). According to the climatological conditions in Iran, four different seasons are distinguished including spring (from March to the end of May), summer (from June to the end of August), autumn (from September to the end of November), and winter (from December to the end of February) [5]. 


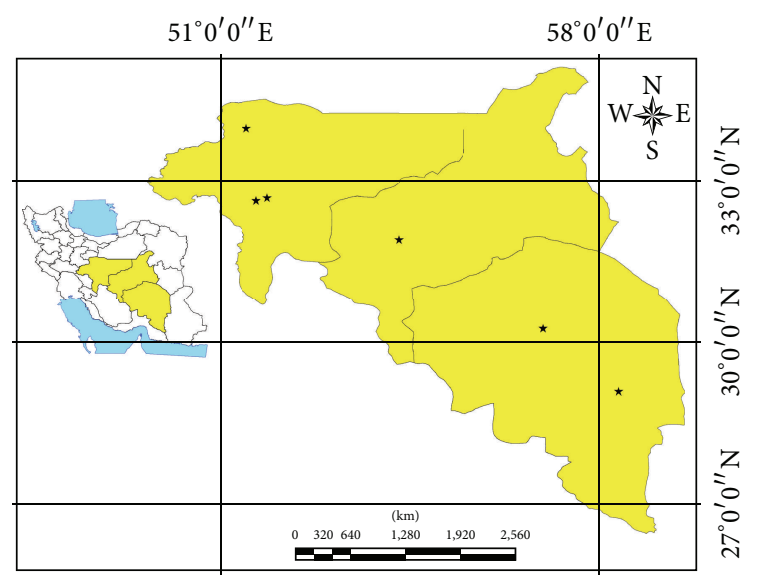

다 Iran
* Case study
Synoptic stations

FIGURE 1: Geographical location of the researched area.

TABLE 1: Varying intensities of drought based on standard precipitation index.

\begin{tabular}{lc}
\hline Standard precipitation index & Index value \\
\hline 2 and more & Strongly severe wet years \\
1.5 to 1.99 & Severe wet years \\
1 to 1.49 & Moderate wet years \\
-0.99 to 0.99 & Normal \\
-1 to -1.49 & Moderate drought \\
-1.5 to -1.99 & Severe drought \\
-2 and less & Strongly severe drought \\
\hline
\end{tabular}

In this study, the precipitation data obtained from six synoptic stations on a daily and monthly basis over a 30 year statistical period (1982-2011) were used. The standard precipitation index (SPI) is one of the most commonly used indicators of meteorological drought monitoring that has been used extensively in the literature [28]. Among all drought indices, SPI is the most popular one which is widely used throughout the world for the purpose of drought analysis (e.g., [4, 29-31]). The standard precipitation index (SPI) was used for identifying dry periods and statistical analysis (see (1)). This index was developed by Mckee et al. [32] based on the following equation:

$$
\mathrm{SPI}=\frac{P_{i}-\bar{P}}{\mathrm{SD}},
$$

where $P_{i}$ is the precipitation in $i$ th year, $\bar{P}$ is the average precipitation during the statistical period, and SD is the standard deviation of the precipitation series. The positive values of index show precipitation above average while the negative values indicate varying intensities of drought (Table 1).

Afterwards, using SPI, drought, wet, and normal periods were identified in the study area. In the next phase, assuming a spatial occurrence of more than 50 percent in the area under study, 38 months of wet year, 11 months of dry year, and about 26 months of normal years were identified. To recognize the circulation patterns of the dry and wet years, the principal component analysis (PCA) was applied to geopotential height data at $500 \mathrm{HPa}$ level. The PCA has three main outcomes: spatial patterns (factor loading), temporal pattern (component scores), and variance array of components. The goal of this analysis is to reduce the size of data and identify the most important temporal and spatial patterns for the geopotential height variance at $500 \mathrm{HPa}$ level over the study area [33]. In the next phase, the cluster analysis was applied to the data using Ward's method to detect mapping patterns of wet and drought year separately; to have a clear understanding of the patterns in the drought and wet periods, the daily data belonging to the selected months were used. To this end, PCA was employed to identify geopotential height mapping patterns with using factor loading and then cluster analysis was applied on component scores to get mapping patterns in the wet and drought years separately.

In each cluster, therefore, a particular day based on the highest intraclass correlation was introduced as circulation patterns. Then, the map of circulation patterns was extracted and analyzed in the framework of the introduced coordinates. In the cluster analysis process, the Euclidean distance equation was to calculate the distance:

$$
d_{i, j}=\sqrt{\sum_{p=1}^{n}\left(X_{i, p}-X_{j, p}\right)^{2}},
$$

where $n$ is the number of individuals, $X_{i, p}$ is the value of $p$ th variable in $i$ th day, and $X_{j, p}$ is the value of $p$ th variable in $j$ th day. To calculate the integration or binding of data, the Ward equation was used:

$$
\begin{aligned}
d\left(C_{i} \cup C_{j}, C_{k}\right)= & \frac{n_{i}+n_{k}}{n_{i}+n_{j}+n_{k}} d\left(C_{i}, C_{k}\right) \\
& +\frac{n_{i}+n_{k}}{n_{i}+n_{j}+n_{k}} d\left(C_{i}, C_{k}\right) \\
& -\frac{n_{i}+n_{k}}{n_{i}+n_{j}+n_{k}} d\left(C_{i}, C_{j}\right),
\end{aligned}
$$

where $d$ is Euclidean distance of clusters and $i, j, k(C=$ Cluster) $-C_{i}, C_{j}, C_{k}$ are each a separate cluster [34].

The data on geopotential height at $500 \mathrm{HPa} 609 * 306$ arrays (306 indicates the days and 609 the arrangement of points) was selected with a $2.5 * 2.5$-degree spatial separation, and the data on geopotential height at $500 \mathrm{HPa}$ level in the domain of 10 to 80 degrees of east longitude and 20 to 70 degrees of north latitude were derived from the website of http://www.esrl.noaa.gov/psd/data/gridded/ (National Oceanic \& Atmospheric Administration) [35].

\section{Results and Discussions}

3.1. Drought Period. To achieve drought patterns by SPI drought index, 11 months in the statistical period of the study area were identified and the data on geopotential height at 
TABLE 2: Component percentages estimated from principal component analysis.

\begin{tabular}{lcccccccccccc}
\hline Components & 1st & 2nd & 3rd & 4th & 5th & 6th & 7th & 8th & 9th & 10th & 11th & 12th \\
\hline Expression percentage & 27.8 & 13.2 & 11.6 & 10.4 & 8 & 6.4 & 4.8 & 3.2 & 2.3 & 1.8 & 1.4 & 1.1 \\
\hline Eigenvalues $\left(e^{-14}\right)$ & -7.39 & -3.33 & -2.58 & -2.23 & -1.97 & -1.89 & -1.8 & -1.53 & -1.41 & -1.23 & -1.01 & -9.61 \\
\hline
\end{tabular}

$500 \mathrm{HPa}$ level were extracted based on a dry daily basis from NASA classified data to be used for the principal components and cluster analyses. Based on the principal component analysis, for the classification of map patterns, the correlation matrix and Varimax rotation were used; therefore, rotational components were transformed into maps to reveal their map patterns. According to the variance array of principal component analysis, the percentage explained by each data component of geopotential height at $500 \mathrm{HPa}$ was calculated (Figures 2-5). Accordingly, 92 percent of data variance in geopotential height can be explained by 12 factors. For the sake of brevity, the components with low percentage were excluded from the analysis and only 6 components were included in each analysis.

According to the final results, six components that explained 78 percent of variance in data were incorporated in the analysis (Table 2).

The PCl explains 27.8 percent of data variance of geopotential height at $500 \mathrm{HPa}$ in dry periods. The spatial pattern of this component indicates that the positive phase of the North Sea-Caspian represents the subpolar low height, with their movement towards lower latitudes contributing to the expansion of high height to lower latitudes. In the study area, the positive phase shows high elevation center which is characterized by air stability (Figure 2). The PC2 explains 13.2 percent of data variance of geopotential height at $500 \mathrm{HPa}$ level in dry periods. The spatial pattern of the second component indicates the multipolarity of phases, and the positive phase that infiltrates Iran from Northeast can be Siberian high. Also, the phase consolidated in the area and southern Iran is a high height pattern that can be attributed to subtropical high pressure weather front (Figure 3). The PC3 explains 11.6 percent of data variance of geopotential height at $500 \mathrm{HPa}$ level. The spatial pattern of the third component shows the formation of several centers with varying phases in which the most important center affecting the study area is a positive phase representing the high elevation sites in the West and Northwest of Europe as the underlying cause of drought (Figure 4). The PC4 explains 10.4 percent of data variance of geopotential height at $500 \mathrm{HPa}$ level. The spatial pattern of the fourth component demonstrates the emergence of a high elevation center over the Mediterranean Sea and the Black Sea, which affects the study area by reinforcing air stability with a subsequent lack of humidity and precipitation (Figure 5). However, we can explain maps of factor loading (positive or negative points) with the other circulation patterns that form or transmit in study area.

3.2. The Cluster Analysis of Circulation Patterns of Drought Periods. Having performed the principal component analysis, the factor scores obtained from the analysis were used for cluster analysis, which was carried out by calculating

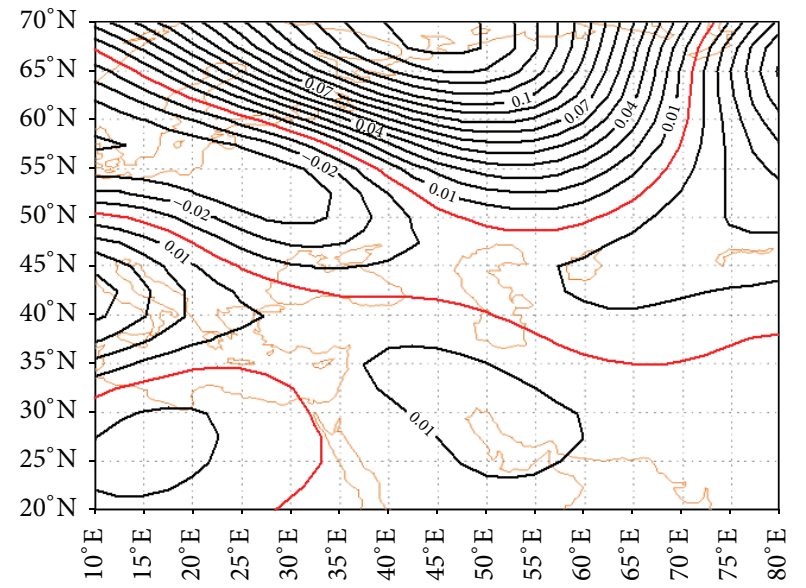

FIgURE 2: The first component of $500 \mathrm{HPa}$ geopotential height level data.

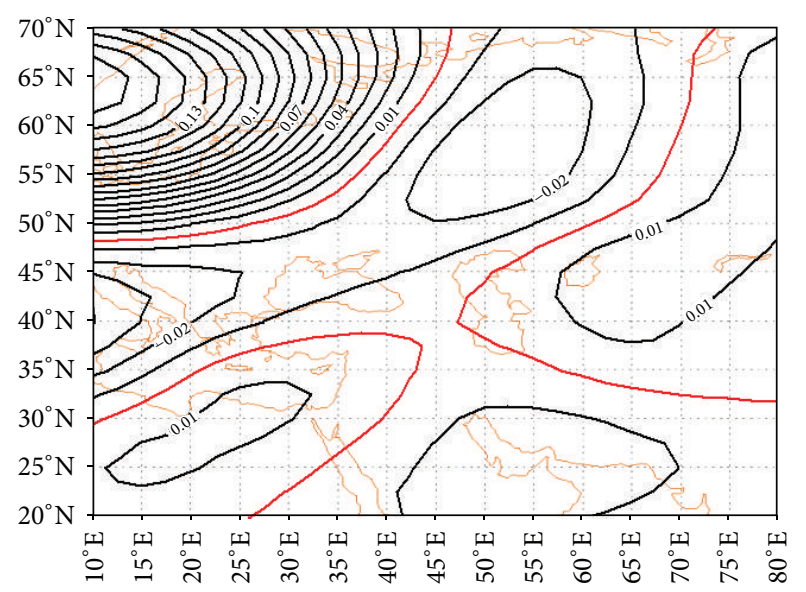

FIGURE 3: The second component of $500 \mathrm{HPa}$ geopotential height level data.

Euclidean distance and Ward bond on the component scores to identify map patterns of drought periods. As such, a single day was chosen in each cluster as the base day or circulation pattern based on the maximum intragroup correlation (Table 3). Then, the map of base days or circulation pattern was extracted based on the specified coordinates and subjected to analysis.

3.2.1. Pattern A. This pattern with a frequency of 26 percent is dominant in winter and early spring and plays an important role in drought event. Here, March 1, 2008, was chosen as the base day or circulation pattern of this cluster based on the correlation analysis. 
TABLE 3: Representative days in each cluster and their properties.

\begin{tabular}{lccccc}
\hline Day & Month & Year & Frequency percent & $\begin{array}{c}\text { Intragroup } \\
\text { correlation }\end{array}$ & $\begin{array}{c}\text { Correlation of } \\
\text { representative day }\end{array}$ \\
\hline 1 & 3 & 2008 & 26 & 0.90271 & 0.93832 \\
11 & 12 & 1993 & 30 & 0.87214 & 0.91763 \\
4 & 12 & 1988 & 15 & 0.89136 & 0.92317 \\
27 & 1 & 1987 & 2 & 0.96543 & 0.97541 \\
15 & 4 & 2001 & 18 & 0.82012 & 0.87655 \\
11 & 2 & 1997 & 9 & 0.93275 & $\mathrm{C}$ \\
\hline
\end{tabular}

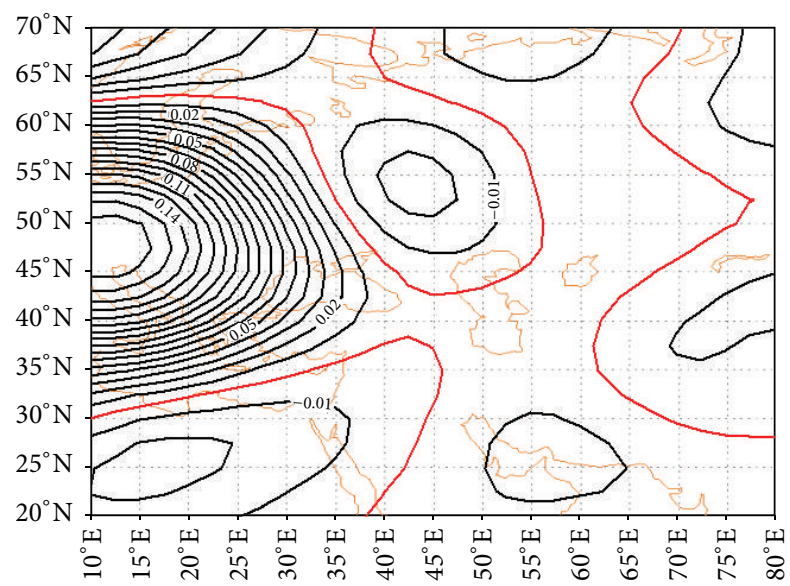

FIgURE 4: The third component of $500 \mathrm{HPa}$ geopotential height level data.

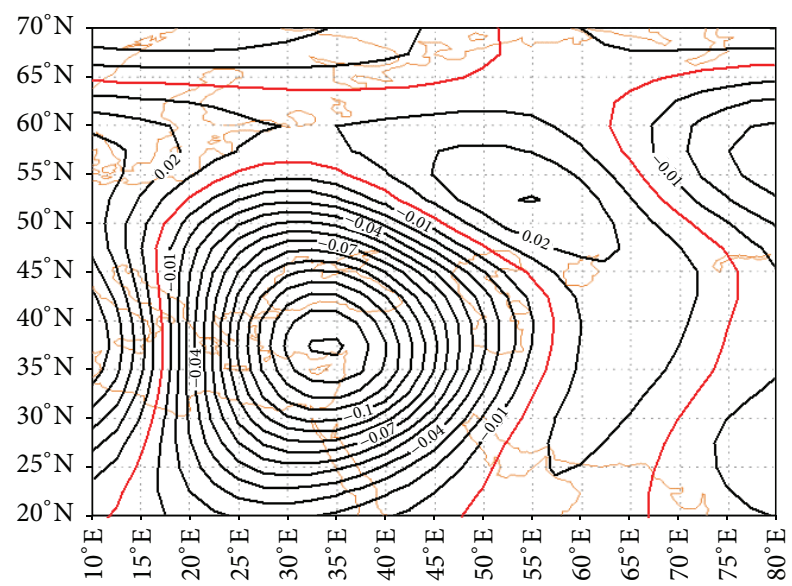

FIGURE 5: The fourth component of $500 \mathrm{HPa}$ geopotential height level data.

The map pattern of $500 \mathrm{HPa}$ level shows that a high elevation center with a closed contour of 580 geopotential decameters (anticyclone system) is shaped in Western Spain in east of Atlas Ocean. Moreover, a trough is formed with the east of Mediterranean Sea and Northwest of Egypt being at its heart. The study area is located in the path of weak ridge axis of Central Iran, with the arrangement of geopotential height curves on the region being in disparity with the trough

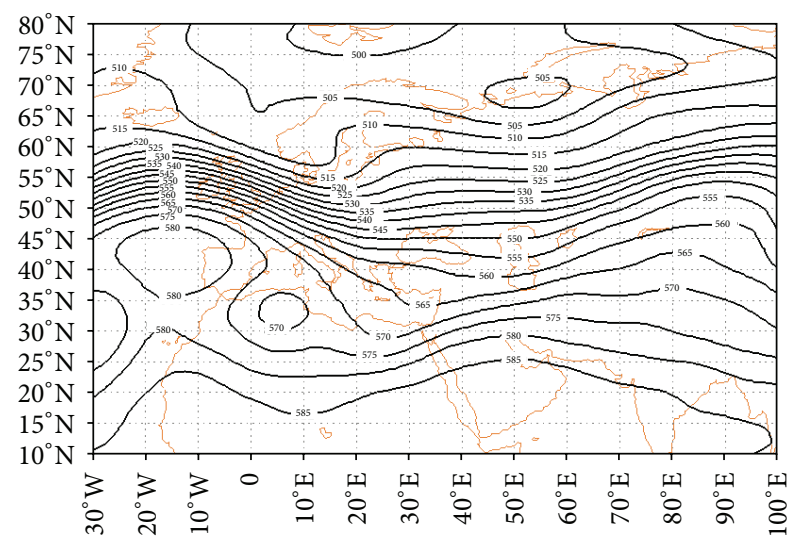

FIGURE 6: $500 \mathrm{HPa}$ geopotential height level map.

and atmospheric waves ridge (Figure 6). The map pattern of sea level pressure shows that there is a high pressure center with closed contour of $1020 \mathrm{HPa}$ on the Northwest of Iran, with the study area being under the influence of this high pressure. Moreover, two relatively strong high pressure systems on Tibet and eastern parts of Atlantic Ocean with a closed contour of $1030 \mathrm{HPa}$ lower than $45^{\circ} \mathrm{N}$ that affect the area under study. In any case, these subpolar highs and lows are largely extended to the lower latitudes in the northwest (Figure 7). According to the map pattern, it can be concluded that there is a dominant high pressure center on the study area at the sea level which reinforces the stability of the area. Also, at $500 \mathrm{HPa}$ level, a weak ridge is formed on the west of Persian Gulf which is extended over the study area. The atmospheric arrangement in this pattern is indicative of the air stability in the area which is the main cause of drought event.

3.2.2. Pattern $B$. This pattern with a frequency of 30 percent is dominant in winter and early spring and plays a critical role in the drought events. This pattern is identical to the first pattern in terms of time, but weaker in terms of intensity. Here, December 11, 1993, was chosen as the base day or circulation pattern of this cluster based on correlation analysis. The map pattern of geopotential height at $500 \mathrm{HPa}$ level indicates the prevalence of weak atmosphere currents over Iran. Also, the study area is under the upper convergence of east ridge, and the extent of trough penetration and ridge of upper latitude reaches $40^{\circ} \mathrm{N}$ with its axis being in the Northwest of the Persian Gulf. Further, it indicates that the study area 


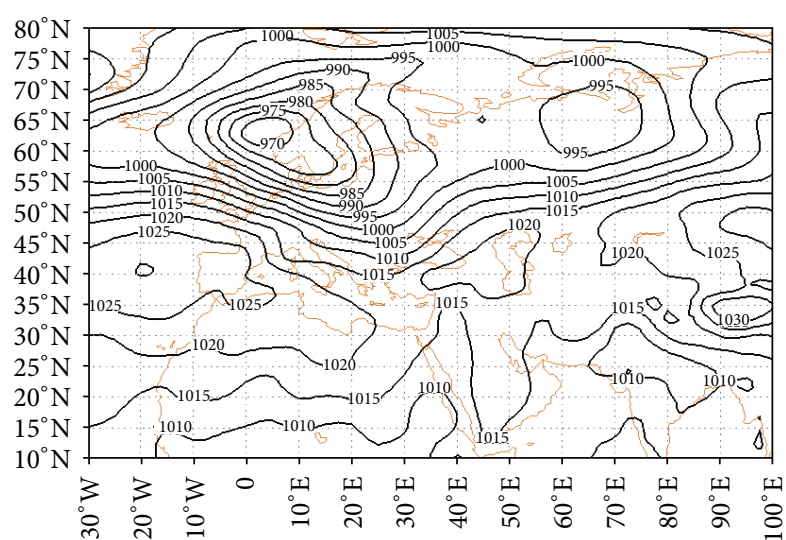

Figure 7: Sea level pressure map.

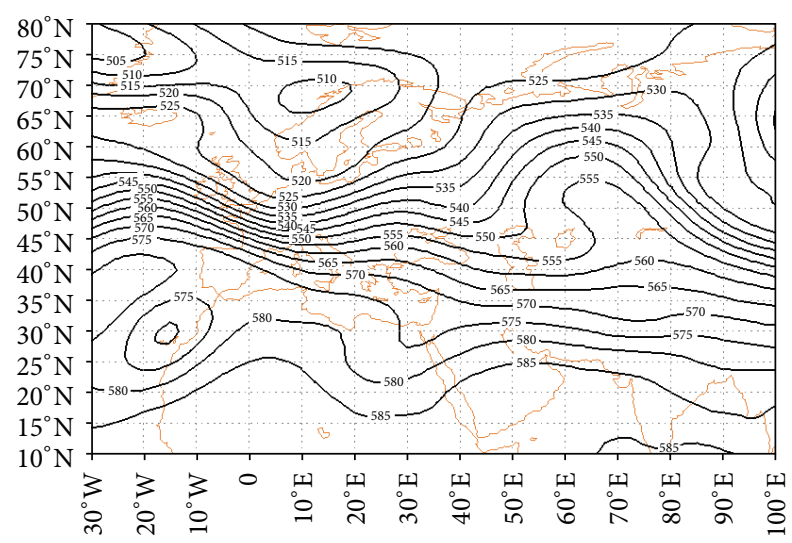

FIGURE 8: $500 \mathrm{HPa}$ geopotential height level map.

is not under the influence of a trough surrounding the Mediterranean Sea and Northern Africa (Figure 8). The map pattern of sea level pressure shows that low subpolar current is extended to north of Mediterranean Sea, and there is a high pressure current of the northeast center extending over Baikal lake with closed contour of $1040 \mathrm{HPa}$ as well as a high pressure center in Northwest of Iran with a closed contour of $1025 \mathrm{HPa}$ expanding in this pattern (Figure 9). Therefore, the surface divergence and upper convergence in this pattern prepare the grounds for the appearance of clear weather with scarce precipitation in the area that constitutes one of the underlying causes of drought event.

3.2.3. Pattern C. This pattern with 15 percent frequency is often observed in January. Here, December 4, 1998, was chosen as the base day or circulation pattern of this cluster based on correlation analysis. The map pattern of geopotential height at $500 \mathrm{HPa}$ level shows that a barrier in meridian $40^{\circ}$ east produces changes in the direction of atmospheric currents in two directions of trough and ridge, and the study area is located in the direction of lower latitudes currents and in east ridge. The study area is located in the path of low latitude currents in the east of ridge or under the convergence area (Figure 10). The map pattern of sea level pressure shows that a strong high pressure in North of the Caspian Sea (40

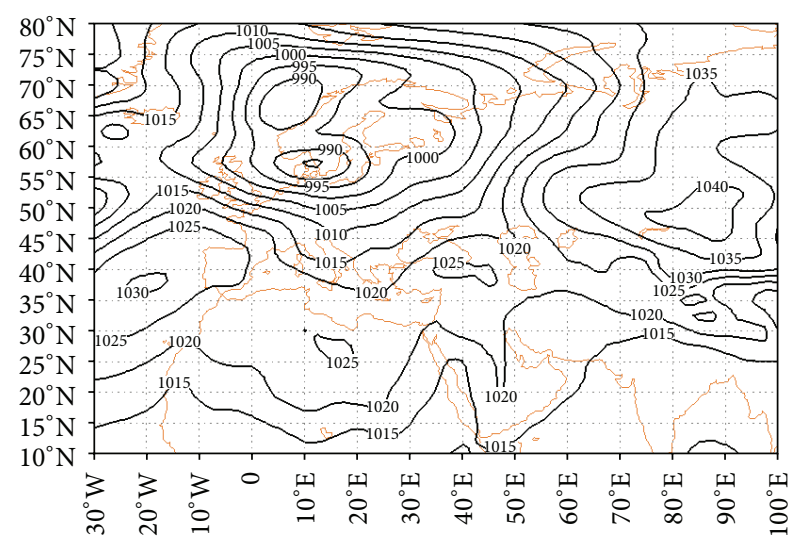

FIGURE 9: Sea level pressure map.

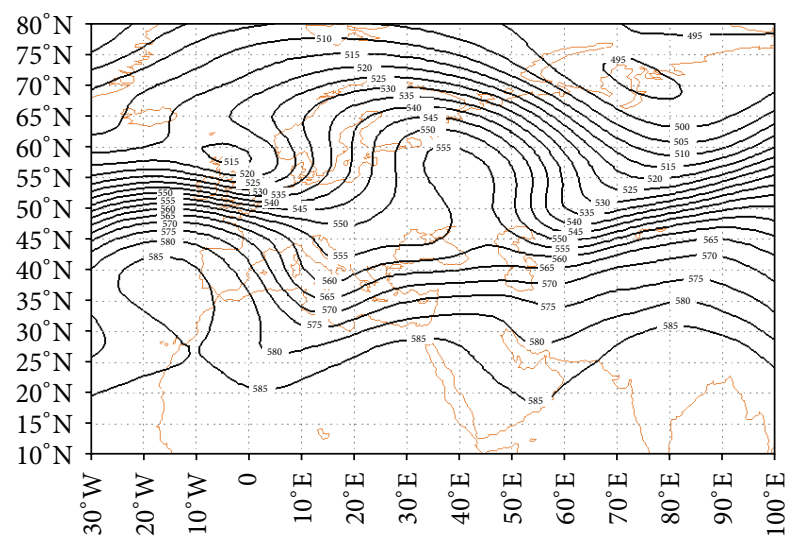

FIgURE 10: $500 \mathrm{HPa}$ geopotential height level map.

degrees east longitude and 55 degrees north latitude) with a closed contour of $1030 \mathrm{HPa}$ is formed, and due to the slow progress of this system in $500 \mathrm{HPa}$ level, atmosphere currents are divided into two directions with the high pressure current extending to Iran and the study area (Figure 11). This pattern in $500 \mathrm{HPa}$ level displays a trough located in the east of the study area and directs the descent of cold weather from upper latitudes over the region, extending at the sea level of Eastern Europe high pressure currents over the area. Thus, in this pattern the condition is not ripe of the entrance and ascent of the humidity, leading to drought condition in January.

3.2.4. Pattern $D$. This pattern with a frequency of 2 percent appears in January-February. Here, January 27, 1987, was chosen as the base day or circulation pattern in this cluster based on correlation analysis. The map pattern of geopotential height at $500 \mathrm{HPa}$ level shows that subpolar lows produce a trough with the Black Sea at its center. In the lower latitudes, atmospheric currents create a ridge on the west of Mediterranean Sea and a trough in the east of Mediterranean Sea and Black Sea that put the area in the east of trough (Figure 12). The map pattern of sea level pressure shows that subpolar lows are extended towards lower latitudes to Black Sea, infiltrating the study area from the Northeast of Africa by producing strong high pressure currents (Figure 13). 


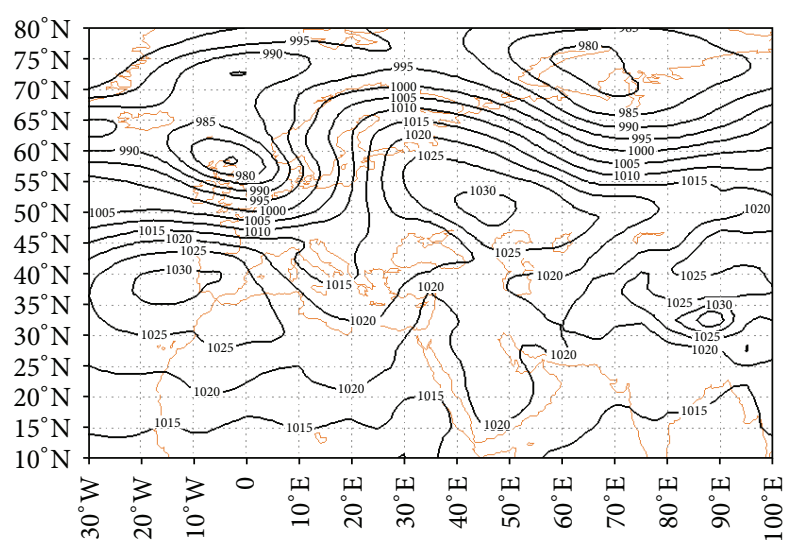

FIGURE 11: Sea level pressure map.

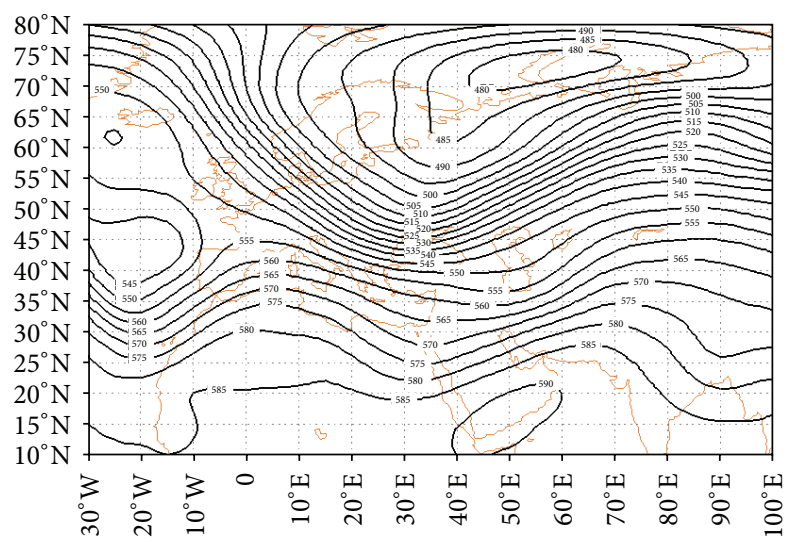

Figure 12: $500 \mathrm{HPa}$ geopotential height level map.

A high elevation in Southeast of Saudi Arabia can be seen with a closed contour of 590 geopotential decameters. According to the above two levels, it can be concluded that this pattern with a frequency of 2 percent has the potential of triggering precipitation, with the humidity of the Mediterranean Sea, Black Sea, and Red Sea entering the area, leading to the precipitation event due to the atmospheric arrangement.

3.2.5. Pattern E. This pattern with a frequency of 18 percent is dominant in spring and plays a crucial role in the appearance of drought event. In this case, April 15, 2001, was chosen as the base day or circulation pattern of this cluster based on correlation analysis. The map pattern of geopotential height at $500 \mathrm{HPa}$ level displays a deep trough with the centrality of the Mediterranean Sea and a ridge surrounded by the west of Persian Gulf and Caspian Sea, in which the study area is located in the east of the ridge (Figure 14). Moreover, a high elevation system (Saudi Arabia anticyclone) is observed in the south of Saudi Arabia with a closed contour of 590 geopotential meters. The map pattern of sea level pressure indicates that a high pressure center of $1015 \mathrm{HPa}$ is formed over the area that hampers the ascent of the surface humidity by a clockwise (divergent) current (Figure 15). Therefore, the upper convergence strengthens the surface divergence that

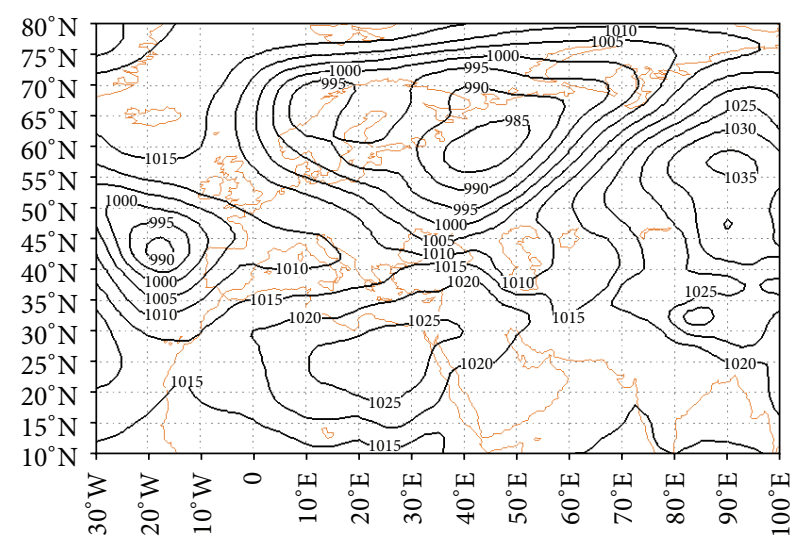

FIGURE 13: Sea level pressure map.

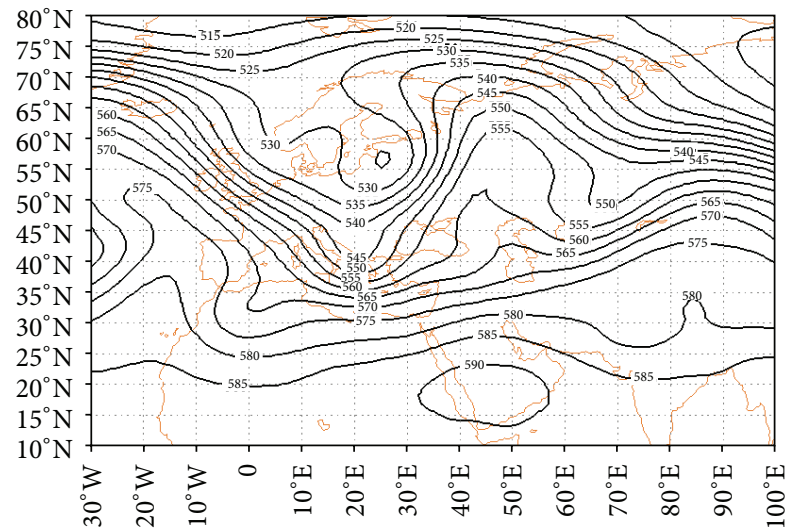

FIgURE 14: $500 \mathrm{HPa}$ geopotential height level map.

increases the durability of this system with no precipitation and clear weather. The absence of upward movements is one of the underlying reasons of stability of weather condition in the region.

3.2.6. Pattern $F$. This pattern with 9 percent frequency is often observed in late January, February, and early March. Here, February 11, 1997, was chosen as the base day or circulation pattern of this cluster based on the correlation analysis. The map pattern of geopotential height at $500 \mathrm{HPa}$ level shows that atmospheric currents produce trough and ridge in two directions with the study being located in the east of trough under the upper divergent region (Figure 16). The map pattern of sea level pressure indicates that a current of eastern Atlantic Ocean highs with a closed contour of $1030 \mathrm{HPa}$ is extended over the study area which is characterized by surface divergence (Figure 17). Therefore, the surface divergence along with the upper divergence undermines the instability of the area.

3.3. Wet Period. According to the variance array of principal component analysis, the percentage explained by each component of geopotential height data at $500 \mathrm{HPa}$ level was 


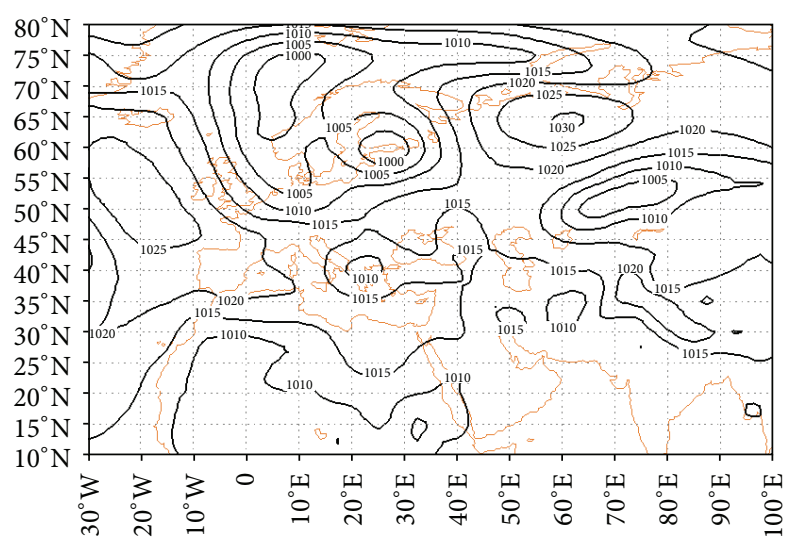

FIGURE 15: Sea level pressure map.

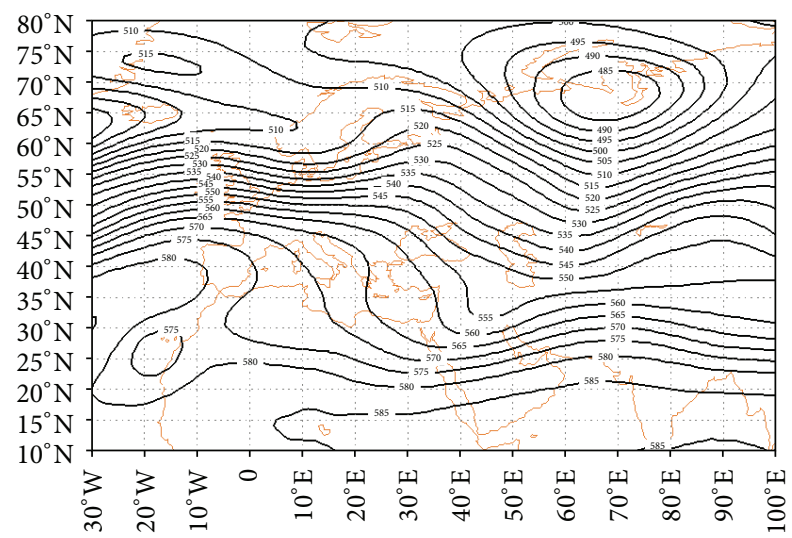

FIGURE 16: $500 \mathrm{HPa}$ geopotential height level map.

calculated for wet years (Figures 18-23). Accordingly, 8 components can explain 94 percent of variance in geopotential height data (Table 4).

The PC1 explains 62.3 percent of data variance of geopotential height data at $500 \mathrm{HPa}$ level in wet years. The spatial patterns of this component showed that there was a positive phase in the study area. The dominant positive phase in Central Iran reveals a low height that provides the condition of atmospheric instability, and the negative phase indicates the polar high and Siberia high with two separate patterns. Therefore, these components have the highest degree of variance among geopotential height data, which makes them the most effective pattern in wet years in the study area (Figure 18). The PC2 explains 11.1 percent of variance in geopotential height data at $500 \mathrm{HPa}$ level in wet years. The spatial pattern of this component suggests that the positive phase dominating the Red Sea and the east of Mediterranean Sea affects the study area, providing the instability condition and humidity ascent in both seas. As such, in wet years, the chief component is the humidity inflow of Red Sea from the southwest towards Iran and the study area (Figure 19).

The PC3 explains 8.1 percent of data variance of geopotential height data at $500 \mathrm{HPa}$ level in wet years. The spatial pattern of this component shows that two simultaneous phases, one with a positive phase over the Mediterranean Sea

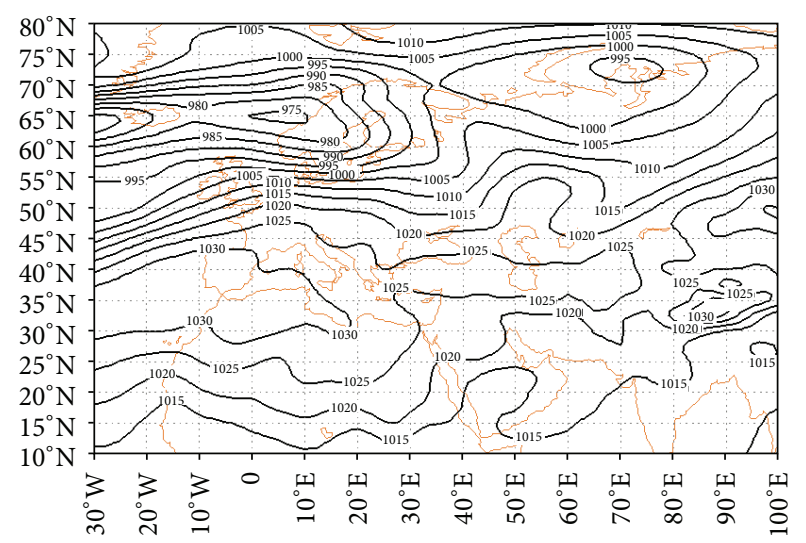

FIGURE 17: Sea level pressure map.

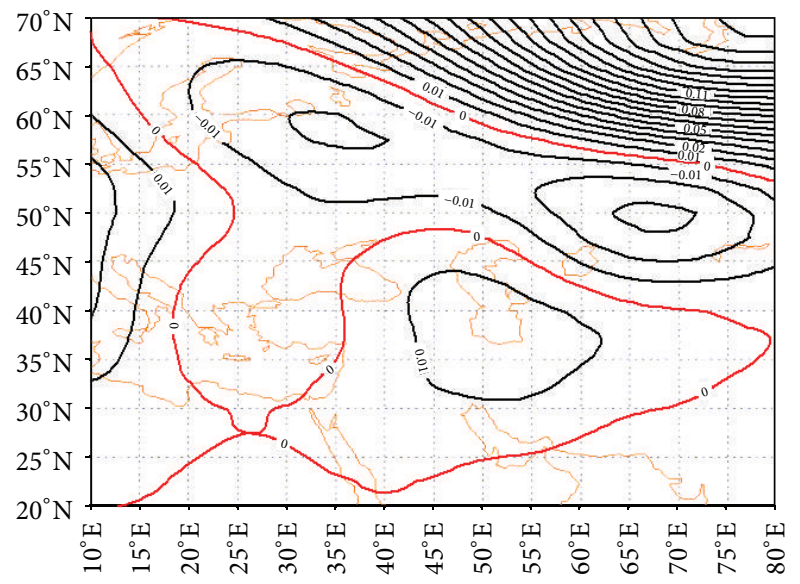

FIGURE 18: The first component of $500 \mathrm{HPa}$ geopotential height level data.

that could be regarded as high elevation and the other with a negative phase over Iran that could be considered as low elevation, are the chief cause of atmospheric instability in the study region (Figure 20). The PC4 explains 3.9 percent of variance in geopotential height $500 \mathrm{HPa}$ of $500 \mathrm{HPa}$ level in wet years. The spatial pattern of this component indicates that there are two important centers with varying phases in the given area: the negative phase expanded from Red Sea to Caspian Sea that affects the study area and the positive phase over the north of Black Sea and Mediterranean Sea. Thus, given the location of both phases, the negative phase can be considered as high elevation such that its anticyclone and clockwise movement lays the ground for the transfer of sea humidity towards the region and the positive phase as subpolar lows which extended to lower latitudes (Figure 21). The PC5 explains 3.2 percent of data variance in geopotential height data at $500 \mathrm{HPa}$ level in wet years. The spatial pattern of this component reveals a center with a negative phase dominating the west of Iran, a low elevation representing the humidity transfer from the Red Sea and Mediterranean Sea, and the positive phase showing the high pressure of the Northwest of Europe (Figure 22). The PC6 explains 2.6 percent of data variance of geopotential height data at $500 \mathrm{HPa}$ 
TABLE 4: Percentage of components estimated from principal component analysis in wet years.

\begin{tabular}{lcccccccc}
\hline Components & First & Second & Third & Fourth & Fifth & Sixth & Seventh & Eighth \\
\hline Expression percentage & 62.3 & 11.1 & 8.1 & 3.9 & 3.2 & 2.6 & 1.3 & 1.2 \\
\hline Eigenvalue $\left(e^{8}\right)$ & 9.69 & 1.29 & 1.715 & 2.023 & 2.289 & 2.461 & 2.847 & 2.998 \\
\hline
\end{tabular}

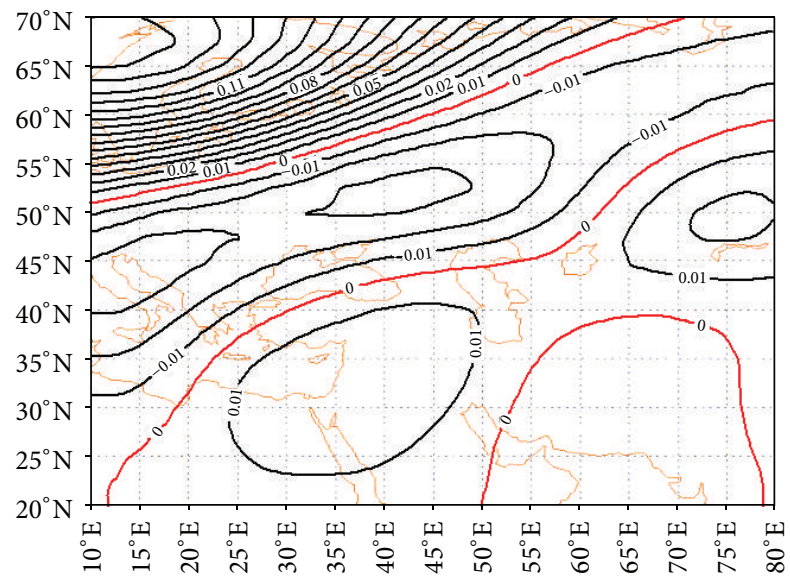

Figure 19: The second component of $500 \mathrm{HPa}$ geopotential height level data.

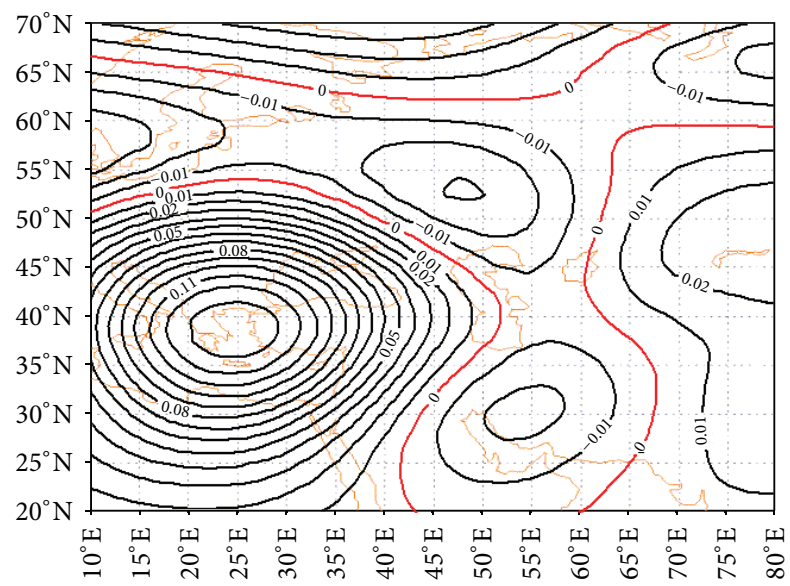

FIgURE 20: The third component of $500 \mathrm{HPa}$ geopotential height level data.

level in wet years. The spatial pattern of this component demonstrates that the center with negative phase in the north of Caspian Sea and Aral Lake is under the influence of Siberia high, while the study area is dominated by low elevation (Figure 23). The PC7 explains 1.3 percent of data variance of geopotential height data at $500 \mathrm{HPa}$ level in wet years. The spatial pattern of this component shows that the center with a dominant negative phase in the region is a low elevation, which can create extremely unstable conditions and increase the probability of heavy precipitation (Figure 24). The PC8 explains 1.2 percent of data variance of geopotential height data at $500 \mathrm{HPa}$ level in wet years. The spatial pattern of this component indicates that the center with a prevailing negative phase in the area is a low elevation that can stir up

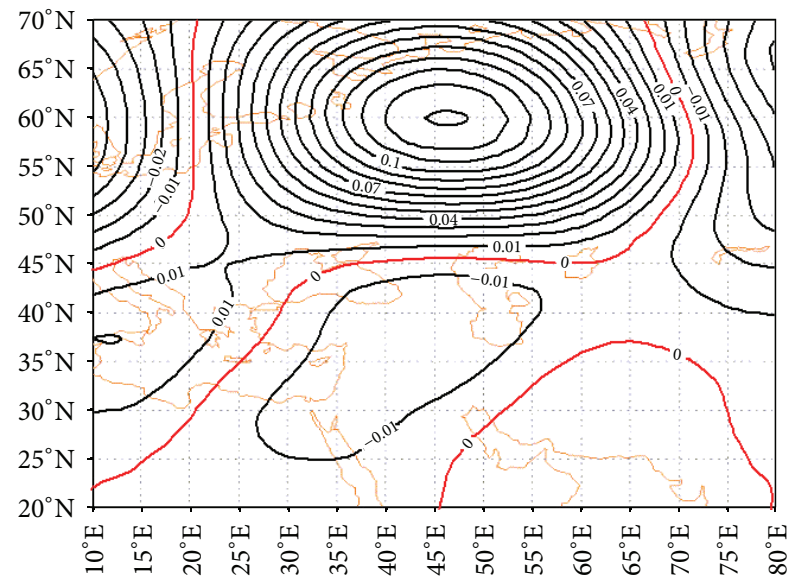

FIGURE 21: The fourth component of $500 \mathrm{HPa}$ geopotential height level data.

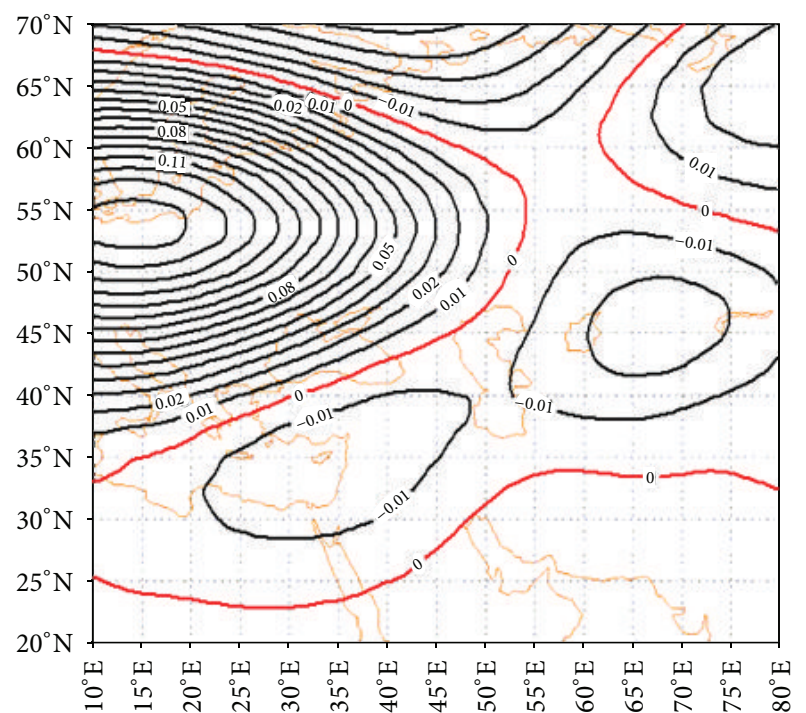

FIGURE 22: The fifth component of $500 \mathrm{HPa}$ geopotential height level data.

severe unstable conditions and provide the grounds for heavy precipitation events (Figure 25). The seventh and eighth components, indicative of heavy precipitations in the study area, can contribute to the emergence of wet years.

3.4. Cluster Analysis of Circulation Patterns of Wet Periods. Cluster exploration on agent amounts of analyzing the main component shows that 4 map patterns in occurrence of wet periods can be identified (Table 5).

3.4.1. Pattern A (Wet Years). This pattern with a frequency of 28 percent in wet years ranks second in map patterns. 
TABLE 5: Representative days obtained from cluster analysis.

\begin{tabular}{lccccc}
\hline Patterns & $\begin{array}{c}\text { Correlation of } \\
\text { representative day }\end{array}$ & $\begin{array}{c}\text { Intergroup } \\
\text { correlation }\end{array}$ & Frequency & Year & Month \\
\hline A & 0.85 & 0.78 & 28 & 1993 & 3 \\
B & 0.89 & 0.84 & 22 & 2009 & 6 \\
C & 0.84 & 0.75 & 35 & 1998 & 3 \\
D & 0.91 & 0.88 & 15 & 2011 & 11 \\
\hline
\end{tabular}

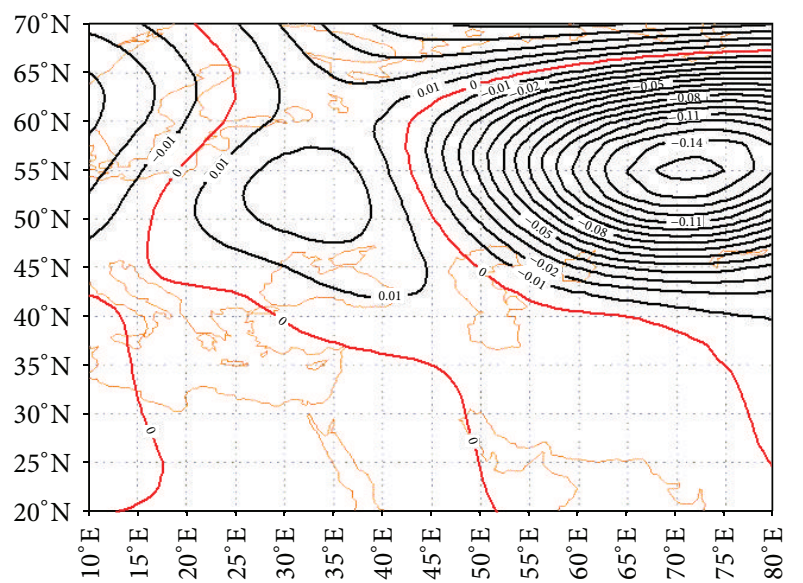

FIgURE 23: The sixth component of $500 \mathrm{HPa}$ geopotential height level data.

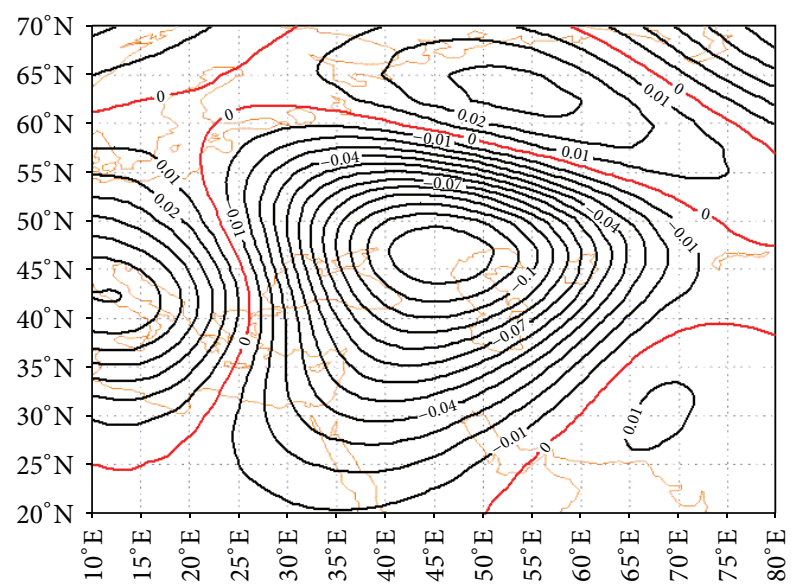

FIgURE 24: The seventh component of $500 \mathrm{HPa}$ geopotential height level data.

In this case, March 27, 1999, was chosen as the base or pattern day based on correlation analysis, and sea level maps of geopotential height at $500 \mathrm{HPa}$ level were analyzed for this day. The map pattern of geopotential height at $500 \mathrm{HPa}$ level suggests that a deep trough is formed in the east of Mediterranean Sea and Red Sea that expands the east trough over the study area. The presence of this cold hole in western part of Caspian Sea with a closed contour of 555 geopotential meters can be observed (Figure 26). Moreover, the high elevation system (anticyclone) with a closed contour of 590 of geopotential decameters was formed on Arab sea, with its

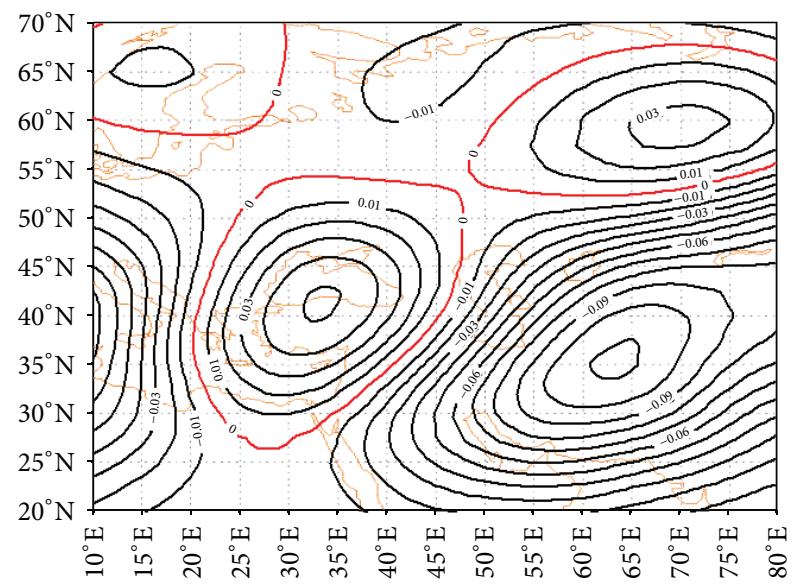

FIGURE 25: The eighth component of $500 \mathrm{HPa}$ geopotential height level data.

clockwise circulation transferring humidity from Arab and Oman Seas toward central part of Iran. The map pattern of sea level pressure shows that Siberia highs dominate the north and east of Iran, where a low pressure center with a closed contour of $1010 \mathrm{HPa}$ is extended over Iran and triggers instability in the region (Figure 27). At the same time, there is a high pressure center on Anatoly mountainous region with a closed contour of $1010 \mathrm{HPa}$. In this pattern, given the sea level pressure and $500 \mathrm{HPa}$ pressure level, it can be concluded that the concomitant of atmospheric levels is involved in the instability of the region, and, in the presence of necessary humidity, there would be precipitation with a significant effect on the wet periods.

3.4.2. Pattern B (Wet Years). This pattern has a frequency of 22 percent in wet periods, with the day June 3, 2009, being chosen as the base or pattern day based on correlation analysis. The map pattern of geopotential height at $500 \mathrm{HPa}$ level shows the appearance of a trough over the Mediterranean Sea, along with a ridge over the north of Caspian Sea. Under these circumstances, the development of atmosphere barriers contributes to the expansion of eastern ridge over the region, leading to the descent of cold currents in Iran (Figure 28). The map pattern of sea level pressure suggests that subpolar lows are extended towards low latitudes, contributing to the extension of Siberia highs and integrative highs (SiberianEuropean) into Iran with the study area being under the influence of high pressure currents (Figure 29). The analysis of the above two levels reveals that, in the middle level of 


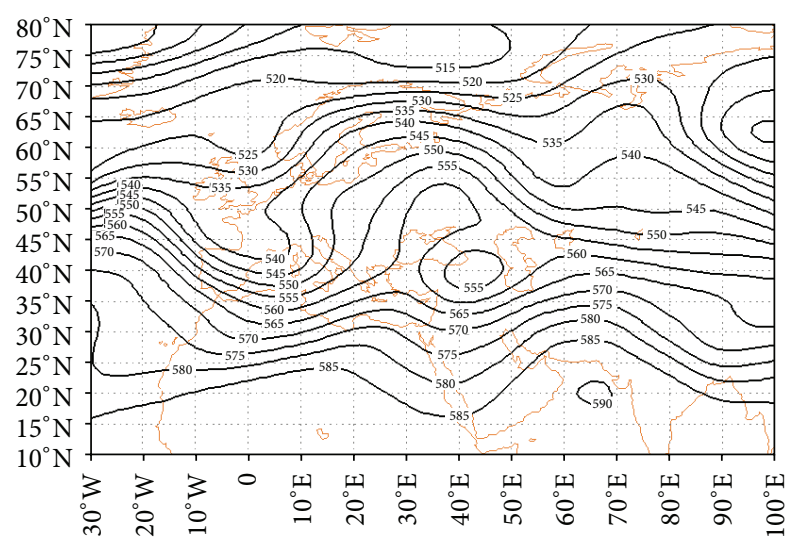

FIGURE 26: Geopotential elevation map at level $500 \mathrm{HPa}$ in the representative day of pattern $\mathrm{A}$.

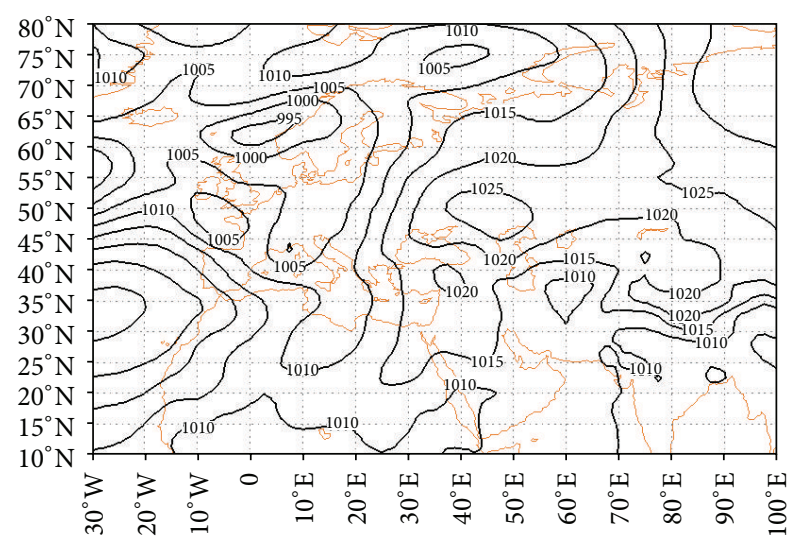

FIGURE 27: Sea level pressure map in representative day of pattern A.

atmosphere, there is cold air descent from high latitudes while high pressure centers are located at the sea level. In this case, the compliance of atmospheric levels leads to coldness and temperature drop in the region, without any precipitation event. Thus, during the wet years in this region, such condition is not far from expectation.

3.4.3. Pattern $C$ (Wet Years). This pattern with a frequency of 35 percent in wet periods ranks first among map patterns. In this case, August 19, 1998, was chosen as the base or pattern day in accordance with the correlation analysis. The map pattern of geopotential height at $500 \mathrm{HPa}$ level shows that (Azor) highs enter Iran from the north of Africa, pushing the air currents to the lower levels, providing stable atmospheric conditions. Also, the subtropical highs with a contour of 590 geopotential meters embrace Iran (Figure 30). The two central cores of this high pressure with a closed contour of 595 geopotential meters are formed in Southwest of Iran and Algeria. The map pattern of sea level pressure reveals that the low pressure centers are extended from Pakistan to the Persian Gulf and the study area (Figure 31). The central core of this low pressure with a closed contour of $1000 \mathrm{HPa}$ is located in the southern coast of Persian Gulf. This pattern

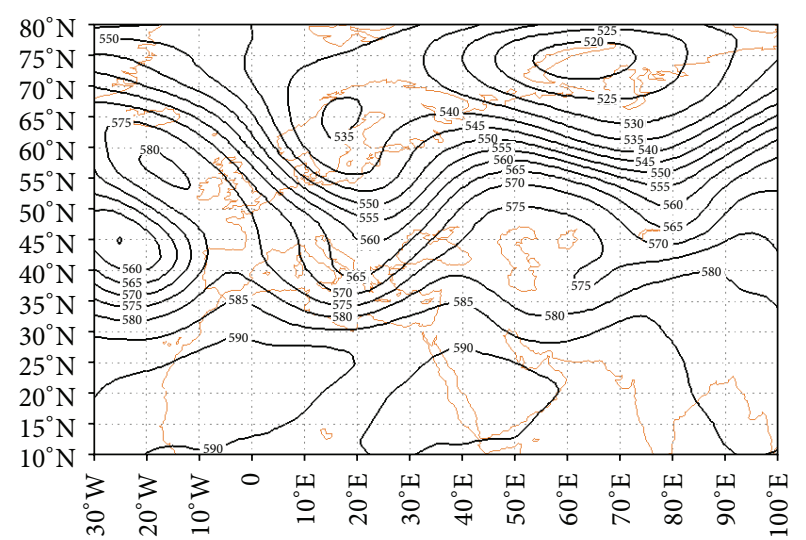

FIGURE 28: Geopotential elevation map at level $500 \mathrm{HPa}$ in the representative day of pattern $B$.

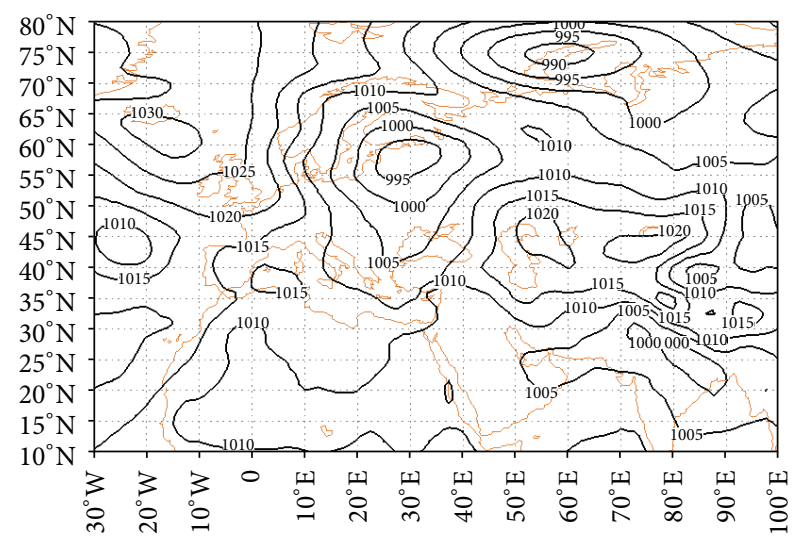

FIGURE 29: Sea level pressure map in representative day of pattern B.

represents the hot period of the year (the first 6 months) with $35 \%$ frequency throughout the year. Therefore, this pattern also lacks the precipitation conditions, which is one of the features of this region.

3.4.4. Pattern $D$. This pattern with a frequency of 15 percent in wet periods ranks fourth among map patterns. In this case, November 23, 2011, was chosen as the representative or pattern day based on the correlation analysis. The map pattern of geopotential height at $500 \mathrm{HPa}$ level reveals the formation of a trough from Caspian Sea to the center of Persian Gulf, with a ridge surrounded by the Mediterranean Sea that pushes the cold air towards Iran, with the probability of precipitation in western regions located under the upper divergence of trough (Figure 32). The map pattern of sea level pressure shows the formation of high pressure center in Western Europe with a closed contour of $1035 \mathrm{HPa}$, with its currents entering Iran. Further, the study area is under the influence of high pressure currents with two high pressure systems observed in the north of Baikal Lake and Tibet plateau (Figure 33). Therefore, the overlapping of these two levels in this pattern prepares the grounds for the cold air descent. If a low pressure center is formed in the region, the presence of eastern trough incites instability, affecting 


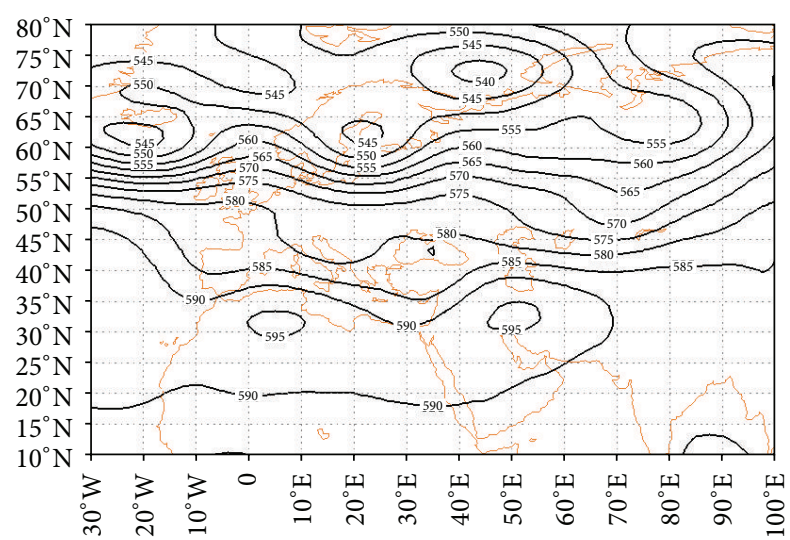

Figure 30: Geopotential elevation map at level $500 \mathrm{HPa}$ in the representative day of pattern $\mathrm{C}$.

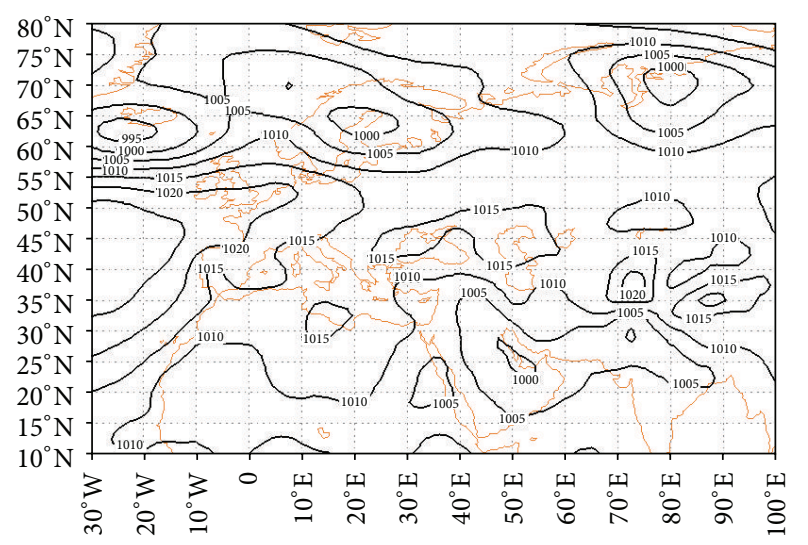

FIGURE 31: Sea level pressure map in representative day of pattern C.

the precipitation event in the eastern part of the study area. The discrepancy of atmospheric levels in the absence of humidity provides a favorable condition for the emergence of dusts, which can significantly affect Iran, especially the study area.

In general, according to the results, this investigation is in agreement with the investigation conducted by Khosh Akhlagh et al. [36] which was conducted in the Southwest of Iran about the spatial position of Mediterranean Sea trough axis. Moreover, in the research done by Atayi [37] the circulation patterns of pluvious period show a deep descent on Iraq and the establishment of the researched region at the eastern part of the descent which is in a good agreement with the results of the present study.

\section{Conclusion}

In this study, an analysis of the factors derived from principal component analysis showed that more than 42 percent of variance in geopotential height at $500 \mathrm{HPa}$ level data was accompanied with the expansion of subtropical lows to lower latitudes, which directed the high elevation regions like Siberian highs to the south, forming high elevation or high pressure currents in the study area. Therefore, the dominance

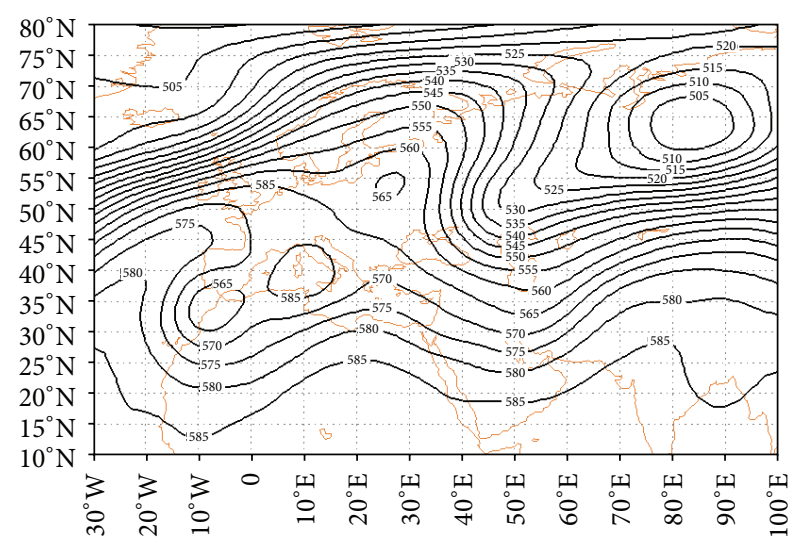

Figure 32: Geopotential elevation map at level $500 \mathrm{HPa}$ in the representative day of pattern $\mathrm{D}$.

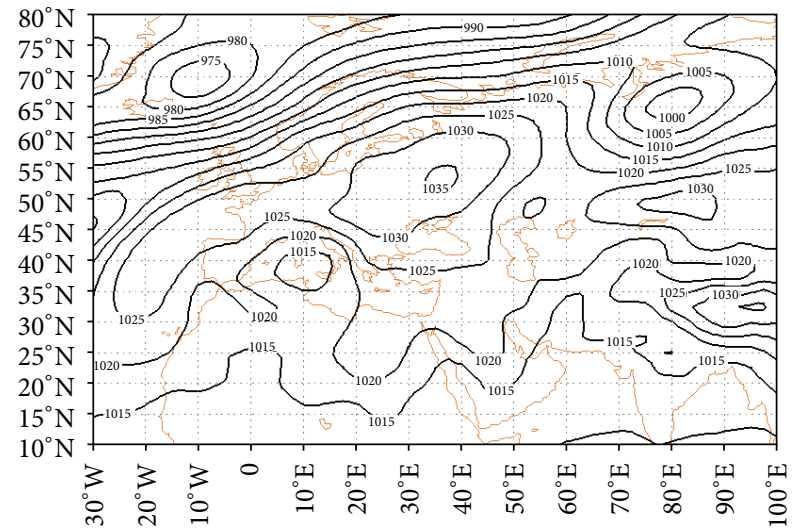

FIGURE 33: Sea level pressure map in representative day of pattern D.

of high elevation cores on the study area, which is characterized by cold air descent and cloudlessness, represents the existence of instability in the area. It contributes to the ascent of the atmospheric humidity and thereby low precipitation and drought events.

Drought is an important and frequent phenomenon in Central Iran and the study area. Although the frequency of drought events in this area based on SPI is much less than wet years, it is due to low monthly precipitations in this region, with each monthly precipitation event disqualifying this region as drought-stricken based on SPI, resulting in wet period or normal condition. The results of principal component analysis showed that 8 components could explain 94 percent of variances in geopotential height data. The results of analyzing the chief components of wet periods suggested that the first component with the highest frequency played the key role in circulation patterns, determining the prominent pattern in the cold period of the year; therefore, this component has the highest variance in geopotential height data, being the most effective pattern in wet period of the region which can explain 62.3 percent of variances. The remaining components, given the negative and positive phases of centers, show the atmospheric instability that 
penetrates the region from Mediterranean Sea, Black Sea, and Red Sea, marking the transition of areas from drought to wet periods. In general, identifying the atmospheric circulation patterns can be effective in weather forecast, regional planning, and climatic models. Therefore, given the paucity of the literature in the study area, more researches are needed to gain deeper insight about the region's weather.

\section{Competing Interests}

The authors declare that they have no competing interests.

\section{References}

[1] B. Alijani, Z. Jafarpour, A. Ali Akbar Bidockti, and A. Mofidi, "Synoptic Analysis of monsoon precipitation circulation patterns in July 1994 in Iran," Geography Sciences Journal, no. 10, pp. 7-38, 2007.

[2] B. Alijani, M. Khosravi, and M. Smaeilnejad, "Synoptic analysis of heavy precipitation of 6 January 2008 in southeast of Iran," Climatology Researches, no. 3-4, pp. 1-12, 2011.

[3] A. Halabian and F. Hossein Ali Pourhazi, "Identifying synoptic condition of partly and pervasive precipitation in western part of Caspian Sea with emphasis on atmosphere thickness patterns," Geography, Environment, Sustainability, no. 3, pp. 101122, 2012.

[4] R. Mirabbasi, E. N. Anagnostou, A. Fakheri-Fard, Y. Dinpashoh, and S. Eslamian, "Analysis of meteorological drought in northwest Iran using the Joint Deficit Index," Journal of Hydrology, vol. 492, pp. 35-48, 2013.

[5] A. Shahabfar, A. Ghulam, and J. Eitzinger, "Drought monitoring in Iran using the perpendicular drought indices," International Journal of Applied Earth Observation and Geoinformation, vol. 18, no. 1, pp. 119-127, 2012.

[6] E. Fatahi and M. Behyar, "Investigation of synoptic patterns of pervasive drought in Chahar-Mahal and Bakhtiyari Province, Iran," Geography Researches, vol. 26, no. 101, pp. 79-100, 2011.

[7] O. Babayi Fini and E. Fatahi, "Classification of synoptic patterns of causing precipitation in the coast of Caspian Sea," Natural Geography Researches, vol. 46, no. 1, pp. 19-42, 2014.

[8] E. K. Mohsen, D. Roshanak, M. Aliakbar, and A. Davood, "Drought assessment in arid regions using vegetation indicesa case study of "Shirkooh of Yazd" in Central Iran," Environmental Sciences, vol. 7, no. 4, pp. 59-72, 2010.

[9] M. Ahmadi, K. Nosrati, and H. Selki, "Drought and its relationship with soil moisture (case study: Isfahan Kabotar Abad)," Geography, vol. 11, no. 38, pp. 77-91, 2013.

[10] A. Galambosi, L. Duckstein, and I. Bogardi, "Evaluation and analysis of daily atmospheric circulation patterns of the 500 HPA pressure field over the southwestern USA," Atmospheric Research, vol. 40, no. 1, pp. 49-76, 1996.

[11] C. Svensson, "Empirical orthogonal function analysis of daily rainfall in the upper reaches of the Huai river Basin, China," Theoretical and Applied Climatology, vol. 62, no. 3-4, pp. 147161, 1999.

[12] P. A. Kassomenos, "Anatomy of the synoptic conditions occurring over southern Greece during the second half of the 20th century. Part I. Winter and summer," Theoretical and Applied Climatology, vol. 75, no. 1-2, pp. 65-77, 2003.

[13] L. Duckstein, A. Bárdossy, and I. Bogárdi, "Linkage between the occurrence of daily atmospheric circulation patterns and floods: an Arizona case study," Journal of Hydrology, vol. 143, no. 3-4, pp. 413-428, 1993.

[14] J. Corte-Real, B. Qian, and H. Xu, "Regional climate change in Portugal: precipitation variability associated with large-scale atmospheric circulation," International Journal of Climatology, vol. 18, no. 6, pp. 619-635, 1998.

[15] R. M. Trigo and C. C. DaCamara, "Circulation weather types and their influence on the precipitation regime in Portugal," International Journal of Climatology, vol. 20, no. 13, pp. 15591581, 2000.

[16] T. Littmann, "An empirical classification of weather types in the Mediterranean Basin and their interrelation with rainfall," Theoretical and Applied Climatology, vol. 66, no. 3-4, pp. 161-171, 2000.

[17] M.-P. Girardin, J. C. Tardif, M. D. Flannigan, and Y. Bergeron, "Synoptic-scale atmospheric circulation and boreal Canada summer drought variability of the past three centuries," Journal of Climate, vol. 19, no. 10, pp. 1922-1947, 2006.

[18] O. Yetemen and T. Yalcin, "Climatic parameters and evaluation of energy consumption of the Afyon geothermal district heating system, Afyon, Turkey," Renewable Energy, vol. 34, no. 3, pp. 706-710, 2009.

[19] U. Büntgen, V. Trouet, D. Frank et al., "Tree-ring indicators of German summer drought over the last millennium," Quaternary Science Reviews, vol. 29, no. 7-8, pp. 1005-1016, 2010.

[20] S. Parry, C. Prudhomme, J. Hannaford, and B. Lloyd-Hughes, "Examining the spatio-temporal evolution and characteristics of large-scale European droughts," in Proceedings of the 3rd BHS International Symposium, pp. 135-142, British Hydrological Society, Newcastle, UK, July 2010.

[21] A. E. Croitoru and F. M. Toma, "Meteorological drought in central Romanian plain (between Olt and Arges Rivers). Case study: year 2000," Riscuri şi Catastrofe, vol. 9, no. 10, pp. 113-120, 2011.

[22] H. Kutiel, "A review on the impact of the North Sea-Caspian Pattern (NCP) on temperature and precipitation regimes in the Middle East," in Survival and Sustainability, pp. 1301-1312, Springer, Berlin, Germany, 2011.

[23] E. Rimkus, J. Kažys, D. Valiukas, and G. Stankūnavičius, "The atmospheric circulation patterns during dry periods in Lithuania," Oceanologia, vol. 56, no. 2, pp. 223-239, 2014.

[24] Z. Peng, Q. J. Wang, J. C. Bennett, P. Pokhrel, and Z. Wang, "Seasonal precipitation forecasts over China using monthly large-scale oceanic-atmospheric indices," Journal of Hydrology, vol. 519, pp. 792-802, 2014.

[25] M. Keshavarz and E. Karami, "Farmers' decision-making process under drought," Journal of Arid Environments, vol. 108, pp. 43-56, 2014.

[26] S. Golian, O. Mazdiyasni, and A. AghaKouchak, "Trends in meteorological and agricultural droughts in Iran," Theoretical and Applied Climatology, vol. 119, no. 3-4, pp. 679-688, 2014.

[27] S. Farhangfar, M. Bannayan, H. R. Khazaei, and M. M. Baygi, "Vulnerability assessment of wheat and maize production affected by drought and climate change," International Journal of Disaster Risk Reduction, vol. 13, pp. 37-51, 2015.

[28] A. Rahmani, S. Golian, and L. Brocca, "Multiyear monitoring of soil moisture over Iran through satellite and reanalysis soil moisture products," International Journal of Applied Earth Observation and Geoinformation, vol. 48, pp. 85-95, 2016. 
[29] M. J. Hayes, M. D. Svoboda, D. A. Wilhite, and O. V. Vanyarkho, "Monitoring the 1996 drought using the standardized precipitation index," Bulletin of the American Meteorological Society, vol. 80, no. 3, pp. 429-438, 1999.

[30] T. Raziei, B. Saghafian, A. A. Paulo, L. S. Pereira, and I. Bordi, "Spatial patterns and temporal variability of drought in Western Iran," Water Resources Management, vol. 23, no. 3, pp. 439-455, 2009.

[31] W. Z. Wan Zin, K. Ibrahim, and A. A. Jemain, "Evaluating the dry conditions in Peninsular Malaysia using bivariate copula," ANZIAM Journal, vol. 51, pp. C555-C569, 2009.

[32] T. B. Mckee, N. J. Doesken, and J. Kleist, "The relationship of drought frequency and duration to time scales," in Proceedings of the 8th Conference on Applied Climatology, pp. 179-184, Anaheim, Calif, USA, January 1993.

[33] A. Masoodian, "30 Years investigation of circulation patterns of atmosphere middle level in Iran," Geography and Regional Development, no. 5, pp. 1-21, 2006.

[34] F. Murtagh and P. Contreras, "Methods of hierarchical clustering," http://arxiv.org/abs/1105.0121.

[35] http://www.cdc.noaa.gov/.

[36] F. Khosh Akhlagh, G. H. Azizi, and M. Rahimi, "The synoptic patterns of wintertime drought and wet period in southwestern of Iran," Journal of Geographical Sciences, vol. 12, no. 25, pp. 5777, 2012.

[37] H. Atayi, "Identify and analysis of patterns of atmosphere middle level in high rainfall years in Iran," Geography Researches, no. 90, pp. 19-38, 2008. 

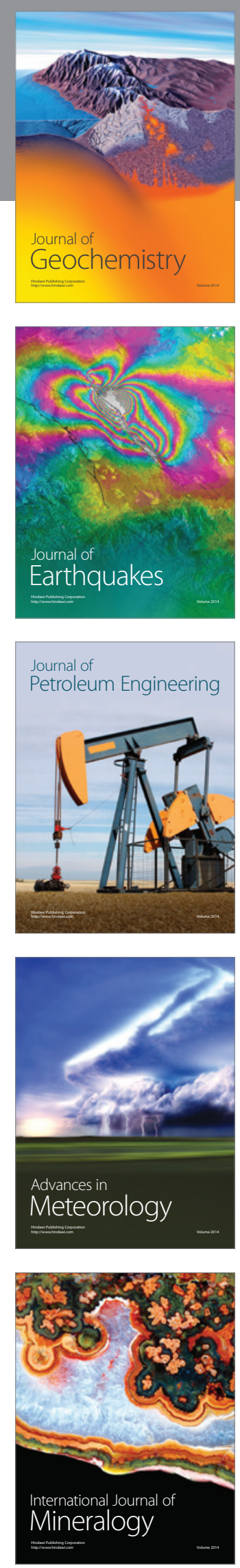
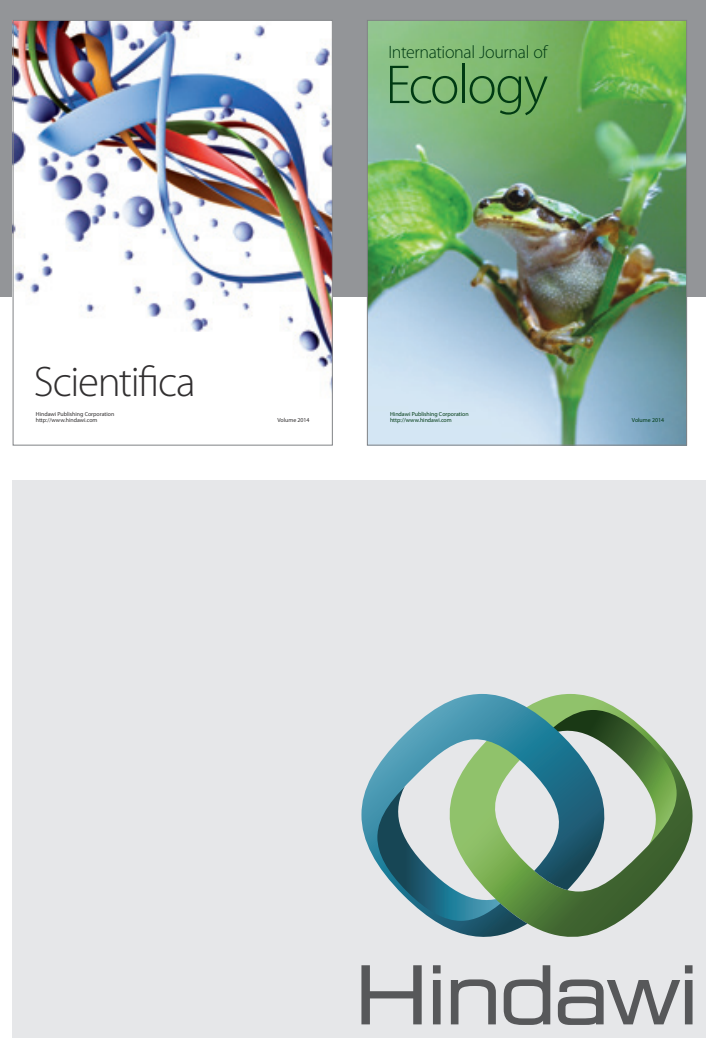

Submit your manuscripts at

http://www.hindawi.com
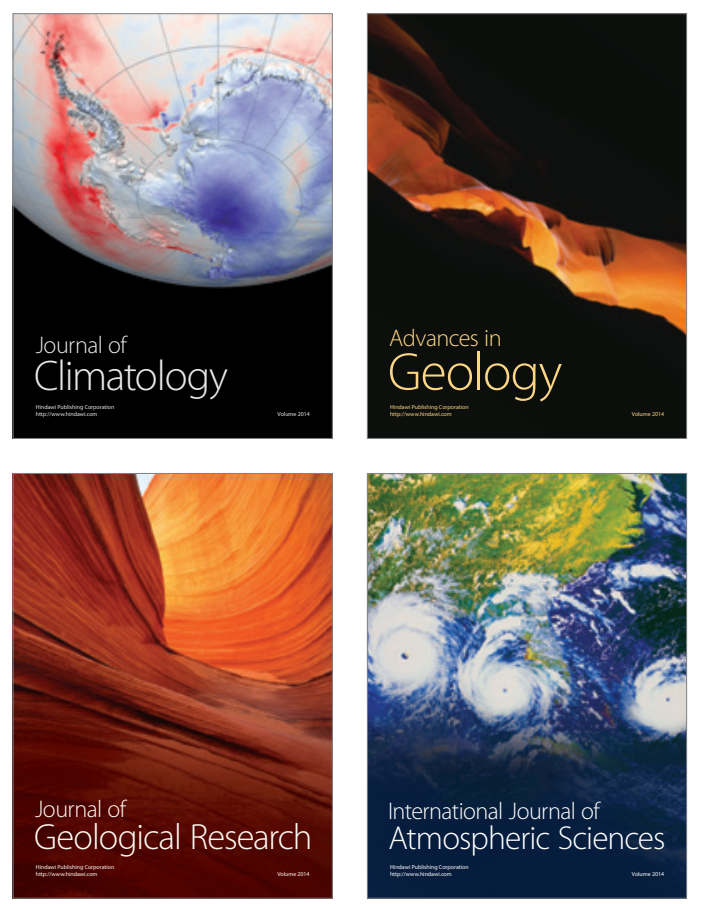

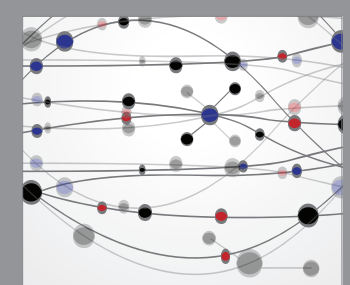

The Scientific

\section{World Journal}
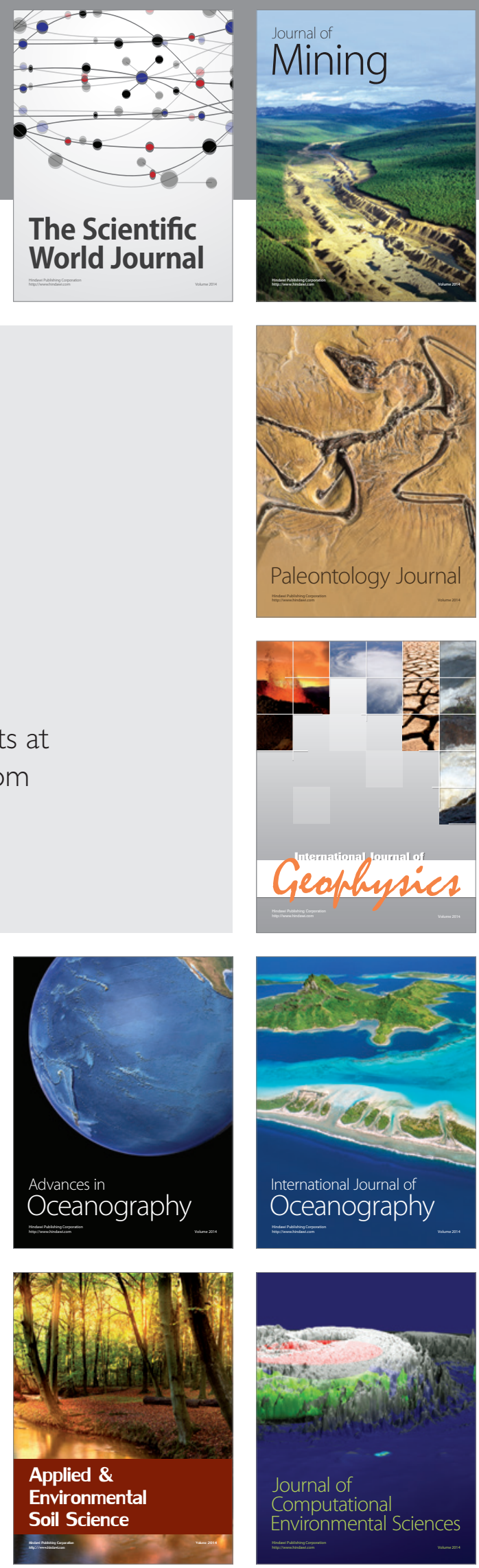